\title{
Efektivitas Penggunaan Laboratorium High Voltage di Politeknik Ilmu Pelayaran (PIP) Semarang
}

\author{
Andy Wahyu Hermanto ${ }^{a *}$, M. Imroni Mubin ${ }^{b}$, Achmad Ridwan

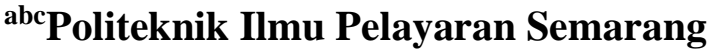 \\ a*Email: andy@pip-semarang.ac.id \\ ${ }^{b}$ Email: ronie.dephub.pip.smg@gmail.com \\ 'Email: ridwannahmad50@gmail.com
}

\begin{abstract}
ABSTRAK
Politeknik Ilmu Pelayaran (PIP) Semarang merupakan perguruan tinggi yang menyelenggarakan Pendidikan vokasi di bidang pelayaran. Laboratorium high voltage merupakan sarana penunjang praktik peralatan kelistrikan di atas kapal yang berbasis tegangan tinggi $6,6 \mathrm{Kv}$. Berdasarkan hasil pengamatan dan observasi awal peneliti, diketahui bahwa penggunaan Laboratorium high voltage selama tahun ajaran 2019 sangatlah minim sekali, yaitu 25,5 jam selama 1 tahun. Tujuan penelitian ini adalah untuk mengetahui penggunaan laboratorium high voltage di PIP Semarang, kendala apa saja yang dihadapi dalam penggunaan laboratorium high voltage di PIP Semarang, serta upaya yang dilakukan untuk mengatasi kendala yang dihadapi dalam penggunaan laboratorium high voltage di PIP Semarang. Metode penelitian yang digunakan dalam penelitian ini adalah metode kualitatif. Data diperoleh dari hasil penyebaran kuesioner kepada taruna. Di samping itu juga dilakukan wawancara dengan Dosen Prodi Teknika. Data sekunder didapatkan dari studi pustaka, observasi, dan dokumentasi. Berdasarkan hasil analisa data maka dapat disimpulkan bahwa penggunaan laboratorium high voltage di PIP Semarang masih belum optimal dan efektif. Hal ini dapat dibuktikan dengan hasil rekapitulasi kuesioner menunjukkan bahwa efektivitas penggunaan laboratorium high voltage sebesar $32 \%$ sangat efektif, $4 \%$ efektif, $60 \%$ kurang efektif, dan $4 \%$ tidak efektif.
\end{abstract}

Kata Kunci: efektivitas, laboratorium high voltage

\section{ABSTRACT}

Semarang Merchant Marine Polytechnic (PIP Semarang) is a university that provides vocational education in the field of shipping. The High Voltage Laboratory is a means of supporting the practice of electrical equipment on board a ship based on a high voltage of $6.6 \mathrm{Kv}$. Based on the results of the researchers' preliminary observations and observations, it is known that the use of the High Voltage Laboratory during the 2019 school year is very minimal, namely 25.5 hours for 1 year. The purpose of this study is to see the use of the High Voltage Laboratory at PIP Semarang, what security is used in the use of the High Voltage Laboratory at PIP Semarang, and the efforts made to overcome the problems used in the use of the High Voltage Laboratory at PIP Semarang. The research method used in this research is a qualitative method. Data obtained from the results of distributing questionnaires to cadets. In addition, interviews were also conducted with Engineering Study Program lecturers. Secondary data obtained from literature study, observation and documentation. Based on the results of data analysis, it can be denied that the use of the High Voltage Laboratory at PIP Semarang is still not optimal and effective. This can be proven by the results of the questionnaire recapitulation showing that the use of the High Voltage Laboratory is $32 \%$ very effective, $4 \%$ effective, $60 \%$ less effective, and $4 \%$ ineffective.

Keywords: effectiveness, high voltage laboratory 


\section{PENDAHULUAN}

Politeknik Ilmu Pelayaran (PIP)

Semarang merupakan perguruan tinggi yang menyelenggarakan pendidikan vokasi di bidang pelayaran. PIP Semarang menyelenggarakan 3 program studi, yaitu Nautika, Teknika dan Tatalaksana Angkutan Laut dan Kepelabuhanan (TALK). Unit Laboratorium, Simulator, dan Workshop merupakan salah satu unit kerja yang ada di PIP Semarang yang memiliki fungsi menyelenggarakan pembelajaran praktik bagi taruna taruni. Tahun anggaran 2018, PIP Semarang telah mengadakan peralatan laboratorium baru yaitu high voltage. laboratorium high voltage merupakan salah satu fasilitas pembelajaran praktik bagi taruna taruni prodi Teknika. Mata kuliah yang terkait dengan laboratorium high voltage adalah sistem kelistrikan kapal dan elektronika.

Berdasarkan hasil pengamatan dan observasi awal peneliti, diketahui bahwa penggunaan laboratorium high voltage selama tahun ajaran 2019 sangatlah minim sekali. Hasil pengamatan ini juga didukung dengan hasil rekapitulasi penggunaan laboratorium high voltage dari Unit Laboratorium, Simulator dan Workshop selama tahun 2019. Berikut ini adalah data rekapitulasi jadwal pembelajaran sistem kelistrikan kapal dan penggunaan laboratorium high voltage:

Dari data tabel berikut dapat kita lihat bahwa total jam pembelajaran pada semester genap adalah 2600 jam dan semester ganjil 2080 jam. Sedangkan jumlah penggunaan laboratorium high voltage selama tahun 2019 sebesar 25,5 jam atau 14 kali pertemuan tatap muka.
Tabel 1. Rekapitulasi Kegiatan Praktik

Pembelajaran Semester Ganjil September 2019 Januari 2020

\begin{tabular}{|c|c|c|c|c|c|c|c|c|c|}
\hline No & Kelas & Senin & Selasa & Rabu & Kamis & Jumat & 1 Minggu & 1 Bulan & 1 Tahun \\
\hline \multicolumn{10}{|c|}{ Dalam Jam } \\
\hline 1 & T I A & & & & & & & & \\
\hline 2 & T I B & & & & & & & & \\
\hline 3 & T I C & & & & & & & & \\
\hline 4 & T I D & & & & & & & & \\
\hline 5 & T IE & & & & & & & & \\
\hline 6 & T IF & & & & & & & & \\
\hline 7 & T I G & & & & & & & & \\
\hline 8 & T I H & & & & & & & & \\
\hline 9 & T III A & & & & & & & & \\
\hline 10 & T III B & & 4 & & & & 4 & 16 & 208 \\
\hline 11 & T III C & & & 4 & & & 4 & 16 & 208 \\
\hline 12 & T III D & & & & & 4 & 4 & 16 & 208 \\
\hline 13 & T III E & & 4 & & & & 4 & 16 & 208 \\
\hline 14 & T III F & 4 & & & & & 4 & 16 & 208 \\
\hline 15 & T III G & 4 & & & & & 4 & 16 & 208 \\
\hline 16 & T III H & & & & 4 & & 4 & 16 & 208 \\
\hline 17 & T VII A & 2 & & & & & 2 & 8 & 104 \\
\hline 18 & T VII B & & & & 2 & & 2 & 8 & 104 \\
\hline 19 & T VII C & & & 2 & & & 2 & 8 & 104 \\
\hline 20 & T VIII A & & & & 2 & & 2 & 8 & 104 \\
\hline 21 & T VIII B & & & & & 2 & 2 & 8 & 104 \\
\hline 22 & T VIII C & & 2 & & & & 2 & 8 & 104 \\
\hline & OTAL & 10 & 10 & 6 & 8 & 6 & 40 & 160 & 2080 \\
\hline
\end{tabular}

Sumber : Rekapitulasi jadwal prodi

Tabel 2. Rekap Kegiatan Praktik Pembelajaran Semester Genap Februari - Juni 2019

\begin{tabular}{|c|c|c|c|c|c|c|c|c|c|}
\hline No & Kelas & Senin & Selasa & Rabu & Kamis & Jumat & 1 Minggu & 1 Bulan & 1 Tahun \\
\hline \multicolumn{10}{|c|}{ Dalam Jam } \\
\hline 1 & T II A & & 4 & & & & 4 & 16 & 208 \\
\hline 2 & T II B & & & & 4 & & 4 & 16 & 208 \\
\hline 3 & T II C & 4 & & & & & 4 & 16 & 208 \\
\hline 4 & T II D & & 4 & & & & 4 & 16 & 208 \\
\hline 5 & TIIE & & & 2 & 2 & & 4 & 16 & 208 \\
\hline 6 & T II F & 2 & 2 & & & & 4 & 16 & 208 \\
\hline 7 & T III G & & & & & 4 & 4 & 16 & 208 \\
\hline 8 & T II H & 4 & & & & & 4 & 16 & 208 \\
\hline 9 & T IV A & & & 2 & & & 2 & 8 & 104 \\
\hline 10 & T IV B & & & & & 2 & 2 & 8 & 104 \\
\hline 11 & T IV C & & & 2 & & & 2 & 8 & 104 \\
\hline 12 & T VII A & & & 2 & & & 2 & 8 & 104 \\
\hline 13 & T VII B & 2 & & & & & 2 & 8 & 104 \\
\hline 14 & T VII C & & 2 & & & & 2 & 8 & 104 \\
\hline 15 & T VIII A & & 2 & & & & 2 & 8 & 104 \\
\hline 16 & T VIII B & & & & 2 & & 2 & 8 & 104 \\
\hline 17 & T VIII C & & 2 & & & & 2 & 8 & 104 \\
\hline \multicolumn{2}{|c|}{ TOTAL } & 12 & 16 & 8 & 8 & 6 & 50 & 200 & 2600 \\
\hline
\end{tabular}

Sumber : Rekapitulasi jadwal prodi

Tabel 3. Rekapitulasi penggunaan Laboratorium High Voltage

\begin{tabular}{|c|l|c|c|c|}
\hline No & \multicolumn{1}{|c|}{ BULAN } & $\begin{array}{c}\text { LAMA PEMAKAIAN } \\
\text { (Dalam Jam) }\end{array}$ & $\begin{array}{c}\text { TOTAL } \\
\text { PENGGUNAAN }\end{array}$ & $\begin{array}{c}\text { JUMLAH } \\
\text { PESERTA }\end{array}$ \\
\hline 1 & JANUARI & 2 & 1 & 18 \\
\hline 2 & FEBRUARI & 2 & 1 & 9 \\
\hline 3 & MARET & 1 & 1 & 23 \\
\hline 4 & APRIL & 4,5 & 3 & 74 \\
\hline 5 & MEI & 4 & 2 & 49 \\
\hline 6 & JUNI & 2 & 1 & 25 \\
\hline 7 & JULI & 5 & 2 & 50 \\
\hline 8 & AGUSTUS & 1 & 1 & 28 \\
\hline 9 & SEPTEMBER & 2 & 1 & 11 \\
\hline 10 & OKTOBER & 2 & 1 & 24 \\
\hline 11 & NOVEMBER & 0 & 0 & 0 \\
\hline 12 & DESEMBER & 0 & 0 & 0 \\
\hline & & $\mathbf{2 5 , 5}$ & $\mathbf{1 4}$ & $\mathbf{3 1 1}$ \\
\hline
\end{tabular}

Sumber : Data penggunaan laboratorium 
Beberapa hasil penelitian terdahulu yang bisa dijadikan referensi dalam penelitian ini adalah sebagai berikut:

1. Misnawaty Usman, Ambo Dalle, Laelah Azizah, Ernawati, 2020, penelitian dengan judul "Efektivitas Penggunaan Laboratorium Bahasa Dalam Pembelajaran Keterampilan Menyimak Bahasa Jerman Mahasiswa Prodi Pendidikan Bahasa Jerman" Fbs-Unm, Hasil analisis dengan uji-t adalah $\mathrm{t}$ hitung $=2,42$ sementara $t$ tabel $=2,086$ jadi $t$ hitung $\geq \mathrm{t}$ tabel $(2,42 \geq 2,086)$. Artinya, $\mathrm{H} 0$ yang menyatakan bahwa penggunaan laboratorium bahasa tidak efektif dalam kemampuan menyimak mahasiswa prodi pendidikan bahasa Jerman yang dinyatakan ditolak. Konsekuensinya H1 yang menyatakan bahwa penggunaan laboratorium bahasa efektif dalam kemampuan menyimak mahasiswa pada prodi pendidikan bahasa Jerman dinyatakan diterima. Hasil penelitian ini dapat disimpulkan bahwa pengajaran dengan menggunakan laboratorium bahasa dapat dijadikan sebagai salah satu media pembelajaran untuk meningkatkan kemampuan menyimak mahasiswa dalam bahasa Jerman.

2. Laila Qonita Ekosari, Trapsilo Prihandono, Albertus Djoko Lesmono, 2018, penelitian dengan judul "Analisis Efektivitas Laboratorium Fisika Dalam Pembelajaran Fisika SMA dan kesesuaiannya dengan Kurikulum 2013”, Hasil review beberapa penelitian tentang laboratorium didapatkan bahwa efektivitas penggunaan laboratorium fisika yang ada di beberapa sekolah masih banyak yang belum efektif. Hal tersebut dikarenakan ketersediaan sarana dan prasarana yang kurang sesuai ataupun karena penggunaan laboratorium dalam kegiatan praktikum yang rendah.

3. Nur Raina Novianti, 2011, penelitian dengan judul "Kontribusi Pengelolaan Laboratorium dan Motivasi Belajar Siswa Terhadap Efektivitas Proses Pembelajaran", hasil penelitian di SMP Negeri dan Swasta Kabupaten Kuningan menunjukkan bahwa kontribusi pengelolaan laboratorium IPA terhadap efektivitas proses pembelajaran menunjukkan tingkat kontribusi yang rendah.

Berdasarkan latar belakang di atas, maka tujuan penelitian ini adalah untuk mengetahui penggunaan laboratorium high voltage di PIP Semarang, kendala apa saja yang dihadapi dalam penggunaan laboratorium high voltage di PIP Semarang, serta upaya yang dilakukan untuk mengatasi kendala yang dihadapi dalam penggunaan laboratorium high voltage di PIP Semarang.

\section{METODE}

Penelitian ini menggunakan metode kualitatif. Metode kualitatif dengan pendekatan studi deskriptif analitik yang dipakai dalam penelitian ini, sebagaimana yang diungkapkan oleh Sugiyono, (2012:3) adalah metode kualitatif untuk mendapatkan data yang mendalam, suatu data yang mengandung makna. Metode kualitatif secara signifikan dapat memengaruhi substansi penelitian. Artinya bahwa metode kualitatif menyajikan secara langsung hakikat hubungan antar peneliti dan informan, objek dan subjek penelitian.

Suatu keadaan dikatakan efektif apabila kesesuaian kegiatan melaksanakan proses dan tujuan pembelajaran itulah yang menunjukkan keefektifan dari proses pembelajaran. Dapat terlaksananya semua tugas dengan estimasi waktu yang ada, tercapainya tujuan pembelajaran, partisipasi yang ditunjukkan oleh peserta didik dan guru, juga menjadi fokus untuk melihat keefektifan (Setiyaningrum, 2015).

Penelitian ini dilaksanakan di Kampus Politeknik Ilmu Pelayaran, 
Jl.Singosari 2A Semarang. Waktu penelitian dilaksanakan mulai bulan Mei sampai dengan September 2020. Sampel penelitian ini adalah taruna prodi teknika dengan populasi 486 taruna, mengutip buku amirin, T., 2011, populasi dan sampel penelitian 4: Ukuran Sampel Rumus slovin, dengan menggunakan rumus slovin, maka akan didapatkan jumlah sampel untuk penelitian ini sebagai berikut :

$$
\begin{aligned}
& \mathrm{n}=\mathrm{N} /\left(1+\mathrm{N} \cdot(\mathrm{e})^{2}\right) \\
& \mathrm{n}=486 /\left(1+486 \cdot(0,05)^{2}\right) \\
& \mathrm{n}=486 /(1+486 .(0,0025)) \\
& \mathrm{n}=486 / 2,215 \\
& \mathrm{n}=219,4 \approx \text { Pembulatan } 220
\end{aligned}
$$

sehingga jumlah sampel yang digunakan pada penelitian ini adalah 220 taruna.

\section{HASIL DAN PEMBAHASAN}

Hasil penelitian ini senada dengan penelitian yang dilakukan oleh Misnawaty Usman, dkk, Tahun 2020, yang menyatakan bahwa penggunaan laboratorium bahasa tidak efektif dalam kemampuan menyimak mahasiswa prodi pendidikan bahasa Jerman.

Sama halnya dengan penelitian Laila Qonita Ekosari, dkk, Tahun 2018. Menyatakan bahwa efektivitas penggunaan laboratorium fisika yang ada di beberapa sekolah masih banyak yang belum efektif.

Penelitian yang sama dari Nur Raina Novianti, 2011, menyatakan bahwa kontribusi pengelolaan laboratorium IPA terhadap efektivitas proses pembelajaran menunjukkan tingkat kontribusi yang rendah.

Dari hasil pengumpulan dan analisa data maka dapat disampaikan hasil penelitian sebagai berikut:

1. Penggunaan laboratorium high voltage di PIP Semarang.

Sesuai dengan data yang diperoleh dari hasil pengumpulan kuesioner maka dapat disimpulkan bahwa penggunaan laboratorium high voltage di PIP Semarang masih belum efektif. Hal ini dapat dibuktikan dengan data yang menunjukkan bahwa $60 \%$ taruna menyatakan bahwa pembelajaran praktik di Laboratorium high voltage belum efektif, sehingga taruna belum familiar dengan laboratorium high voltage. Di samping itu beberapa dosen teknika lebih memilih laboratorium lain untuk melaksanakan pembelajaran praktik mata kuliah sistem kelistrikan kapal. Sehingga persentase penggunaan laboratorium high voltage masih sangat rendah.

2. Kendala yang dihadapi dalam penggunaan laboratorium high voltage di PIP Semarang.

Berdasarkan data yang telah diperoleh dari kuesioner dan hasil wawancara dengan dosen, maka dapat disimpulkan kendala yang dihadapi dalam penggunaan laboratorium high voltage adalah sebagai berikut :

a. Skenario yang diterapkan di laboratorium high voltage terlalu banyak atau panjang sehingga dalam pembelajaran praktik masih kurang efektif.

b. Para dosen/pengajar masih banyak yang belum familiar dengan laboratorium high voltage sehingga lebih memilih laboratorium lain saat mengajar sistem kelistrikan kapal.

c. Di laboratorium high voltage ada beberapa alat atau indikator yang tidak akurat dalam menunjukkan angka atau nilai.

3. Upaya yang dilakukan untuk mengatasi kendala yang dihadapi dalam penggunaan laboratorium high voltage di PIP Semarang.

a. Mempersingkat skenario yang akan diajarkan dan mencari poinpoin penting yang akan digunakan untuk aplikasi di kapal.

b. Diadakan kegiatan pelatihan atau training terkait materi-materi yang akan diajarkan kepada taruna sehingga dosen atau pengajar menjadi familiar dengan laboratorium high voltage. 
c. Diadakan kalibrasi ulang terhadap alat ukur yang terdapat di laboratorium high voltage.

\section{SIMPULAN}

Berdasarkan hasil dan pembahasan yang telah disampaikan sebelumnya, maka dapat disimpulkan sebagai berikut:

1. Penggunaan laboratorium high voltage di PIP Semarang masih belum optimal dan efektif. Hal ini dapat dibuktikan dengan hasil rekapitulasi kuesioner menunjukkan bahwa efektivitas penggunaan laboratorium high voltage sebesar $60 \%$ kurang efektif, $32 \%$ sangat efektif, $4 \%$ efektif, dan $4 \%$ tidak efektif.

2. Kendala yang dihadapi dalam penggunaan laboratorium high voltage di PIP Semarang yaitu skenario yang diterapkan laboratorium high voltage terlalu banyak, pengajar belum familiar dengan laboratorium high voltage, indikator yang kurang akurat di laboratorium high voltage.

3. Upaya yang dilakukan untuk mengatasi kendala yang dihadapi dalam penggunaan laboratorium high voltage yaitu dengan mempersingkat skenario yang sesuai dengan aplikasi kapal, mengadakan pelatihan atau training bagi para dosen atau pengajar, dan melakukan kalibrasi ulang secara rutin untuk keakuratan alat ukur yang digunakan di laboratorium high voltage.

\section{DAFTAR PUSTAKA}

Abdurahmat. (2008). Efektivitas Organisasi Edisi Pertama. Airlangga.

Adi W Gunawan. (2003). Genius Learning Strategy. Gramedia Pustaka Umum.

Amirin, T., .(2011). Populasi Dan Sampel Penelitian 4: Ukuran Sampel Rumus Slovin. Erlangga.

Ari Setyaningrum. (2015). PrinsipPrinsip Pemasaran. CV. Andi Offset.

KBBI. (2016). Kamus Besar Bahasa Indonesia (KBBI).

Laila Qonita Ekosari, Trapsilo Prihandono, Albertus Djoko Lesmono. (2018). Analisis Efektivitas Laboratorium Fisika Dalam Pembelajaran Fisika SMA Dan Kesesuaiannya Dengan Kurikulum 2013.

Misnawaty Usman, Ambo Dalle, Laelah Azizah, Ernawati. (2020). Efektivitas Penggunaan Laboratorium Bahasa Dalam Pembelajaran Keterampilan Menyimak Bahasa Jerman Mahasiswa Prodi Pendidikan Bahasa Jerman Fbs-Unm.

Nur Raina Novianti. (2011). Kontribusi pengelolaan laboratorium dan motivasi belajar siswa terhadap efektivitas proses pembelajaran,

Sejathi. (2011). Faktor Penentu Efektivitas Pembelajaran. Http://Faktor-

FaktorYangMempengaruhiEfe ktivitasPembelajaran.(Online)( 12Juli2017).

Sugiyono. (2012). Metode Penelitian Kuantitatif Kualitatif dan $R \& B$. Alfabet.

Sujarweni, V. Wiratna.( 2014). Metode Penelitian: Lengkap, Praktis, dan Mudah Dipahami. Pustaka Baru Press. 